\title{
Road Traffic Accidents and Injuries Among Form 6 Students in Muar
}

\author{
Article by Roy Rillera Marzo ${ }^{1}$, Geerththanah Vijayakrishnan² \& Jananny Mumudi \\ Vanthen ${ }^{2}$ \\ ${ }^{1}$ Deputy Dean, Master in Public Health, Fellow in Public Health \\ ${ }^{2}$ Doctor of Medicine
}

\begin{abstract}
Introduction: Road traffic accident refers mainly to any accident involving at least one road vehicle, occurring on a road open to public circulation, and in which at least one person is injured or killed. Road traffic accidents are a recognized dominant cause of injury and death among teenagers worldwide and in Malaysia. Road traffic accidents and injuries is a public health problem worldwide. In 2002, there are 1.2 million people die as a result of road traffic accidents and 50 million are injured and disabled. It is also the $11^{\text {th }}$ cause of death in the world and accounts for $2.1 \%$ of all deaths globally.

Methods: This is a descriptive cross sectional study that targeted form six students as our population in 6 different higher secondary schools in Muar with 280 respondents. Data was collected through a 12 items of multiple structured questions and 5 items of feedback questions, which of overall 17 items of questions in our questionnaire

Results: Among 280 respondents, $84.6 \%$ of them had met with an accident. Majority of the respondents are male (90.7\%), Malay (89.9\%), and come from a low income background (97\%). Surprisingly, there are 66 (90.4\%) have not attended a driving lessons while 82 (94.3\%) of them did not have a driving license. Among the entire respondent surveyed, 76 (96.2 \%) of them did not wear seatbelts or helmets. The remaining 43 which is $15.4 \%$ of them had not met with an accident. There is a significant association between motor vehicles accidents towards driving lessons $(P=0.001)$, driving license $(P=0.001)$, usage of seatbelts or helmets $(P=0.001)$

Conclusion: Our study shows that there was a significant association between road traffic accident and injuries with not having a driving license, not attending driving lessons and usage of seatbelts or helmets.

Recommendation: Our government should implement strict rules and tough penalties such as increasing fines and summon as to curb traffic accidents. For the awareness, schools have a role to play by emphasizing the importance on road safety, like usage of seat belts, proper driving practice by organizing awareness campaigns and seminars which is given by road traffic officers. The media also needs to draw the attention of all road users both to dangers and to safe practices on the road.
\end{abstract}

Keywords: Car occupant accidents, Car occupant injuries, late adolescents, Students, Safety belt or helmets

\section{Introduction}

Transportation is the act of moving something from one place to another (Wikipedia, 2015, December 29, Traffic collision). A road traffic accident refers mainly to any accident involving at least one road vehicle, occurring on a road open to public circulation, and in which at least one person is injured or killed. It can also cause serious injuries to the drivers as well as road passengers (Mohd Zakwan, 2011)

Serious injuries are defined as physical injury which creates a substantial risk of death, or which causes serious disfigurement, serious impairment of health, or serious loss or impairment of the function of any bodily organ (Insee, 2015)

Road traffic accidents and injuries is a public health problem worldwide. In 2002, 1.2 million people die as a result of road traffic accidents and 50 million are injured and disabled. 


\section{E-International Journals of Public Health}

Volume 4, Issue 2, 2016

It is also the $11^{\text {th }}$ cause of death in the world and accounts for $2.1 \%$ of all deaths globally (World Report on Road Traffic Injury Prevention, 2004).

Injuries including road traffic accidents are $3^{\text {rd }}$ cause of admission and $5^{\text {th }}$ cause of death in Malaysian government hospitals in 2003. In the year 2003 about 17 people are killed a day (Health Facts, 2003). The incidence rate of motor vehicle accidents in Malaysia 2000 was 107.64 per 10,000 populations (Ministry of Health Malaysia, Malaysia's Health 2002). Motorcars are most commonly involved, followed by motorcycles, lorries/vans (Royal Malaysian Police 2004).

Road traffic accidents are a recognized dominant cause of injury and death among teenagers worldwide and in Malaysia.

A national study in 1996 reported that most of the road injuries occurred among 10-19 years (31.0\%), followed by 20-29 years of age. Death was more common among the young adults, followed by adolescent (Epidemiology of Injuries 1997). In the year 2000, adolescent between 16-20 years were the majority (16.37\%) of those who were involved in road traffic accidents (Royal Malaysian Police 2004).

These road traffic accidents are always beyond control but somehow the Malaysian government has taken an initiative plans and programmes to control this issue, through the existence of road networks in Malaysia (Mohd Zakwan, 2011)

Many consequences can be related to this issue whereby there is great lost in potential healthy years of life of productivity among the youthful group. There is also minimal information on safety practices particularly among adolescent who are also a major road user in the country.

The past study was to determine the prevalence of road traffic accidents and injuries involving motor vehicles among the upper six students in Selangor. It also determines the association between the injured motorcar occupants with related safety factors like usage of the seat belt, having driving lessons and having driving license.(Car occupants accidents and injuries among adolescents in a state in Malaysia, 2005)

When the causes are well known, we have to take some preventive measures to control these phenomena. There is no definite way to put a full stop for this road traffic accidents and injuries but we can prevent them from occurring.

Therefore, it is important to conduct this study to get all the variables as many as possible in number of accident increment every year. This study will propose an appropriate accident prediction model which can be use by any users that can help them in providing the safety precautions and future work for safety issues especially for related agencies and for the road users in the future.

\section{Objective}

\section{General}

To study the road traffic accidents and injuries among Form 6 students in Muar

\section{Specific}

1. To identify socio demographic characteristics affecting the road traffic accident and injuries

2. To determine the risk factors on road traffic accidents and injuries

3. To determine the association between motor vehicle accidents and injuries towards risk factors

\section{Methodology}

\section{Study design}

This was a descriptive, cross-sectional, school based study which was conducted in 6 secondary schools in Muar, district of Johor. 


\section{Sample size determination}

Cluster sampling method was used to select the town from regions in Muar and simple random sampling was used to select the schools in the respective region that are chosen during the cluster sampling. Our target population included in this study were form six students from secondary school in Muar. The survey was conducted among 280 students

\section{Survey instrument}

Data was collected using a structured questionnaire which was distributed to the 6 secondary schools. The questionnaire is self-administrated and an informed consent gotten from all the participants.

A pilot study was carried out to assess the reliability and validity of the pre- tested questionnaire where 20 form six students were given the questionnaires. The cronbach's alpha showed 0.779 which showed that the questionnaire was reliable.

\section{Questionnaire design}

The validated questionnaire which was used in the survey is based in English Medium which was translated into Bahasa Melayu. This is because the medium of instructions of their school were Bahasa Melayu.

The questionnaires partly adapted from a pretested questionnaire used for similar studies carried out in Selangor, Malaysia. It is a 12 item questionnaire which is divided mainly into socio demographic factors, risk factors on road traffic accidents and injuries, and the association between motor vehicle accidents and injuries towards risk factors.

\section{Data analysis procedures}

The data was first coded and interpreted by PASW Statistics Student Version 18. Data analysis included descriptive statistics which was used to describe participants' demographic characteristics, and texts, tables, graphs, percentages or mean was used to present the results.

\section{Ethical consideration}

Medical Research Ethics Committee (MREC) of Asia Metropolitan University will be required to review the protocol to insure full protection of the rights of study subjects. Following the approval by MREC, NMRR (National Malaysian Research Register) registration will be carried out. Upon acquiring the NMRR registration number, the questionnaires were distributed to the study subjects. A covering letter assuring confidentiality of all the information provided accompanied the questionnaires

\section{Results}

Table 1. Sociodemographic Profile

\begin{tabular}{|l|l|l|}
\hline Variables & Frequency (N) & Percentage (\%) \\
\hline Gender & 151 & 53.9 \\
\hline Male & 129 & 46.1 \\
\hline Female & \multicolumn{2}{|l|}{} \\
\hline Ethnicity & 139 & 49.6 \\
\hline Malay & 108 & 38.6 \\
\hline Chinese & 33 & 11.8 \\
\hline Indian & & \\
\hline
\end{tabular}


E-International Journals of Public Health

Volume 4, Issue 2, 2016

\begin{tabular}{|c|c|c|}
\hline \multicolumn{3}{|l|}{ Family Income } \\
\hline Low & 127 & 45.4 \\
\hline Middle & 121 & 43.2 \\
\hline High & 32 & 11.4 \\
\hline \multicolumn{3}{|c|}{ Who taught you to drive? } \\
\hline Family Member & 54 & 19.3 \\
\hline Friends & 71 & 25.4 \\
\hline Qualified Instructor & 155 & 55.4 \\
\hline
\end{tabular}

The sociodemographic of the respondents are shown in Table 1. Out of 280 respondents, $53.9 \%$ were men. Among the participants, Malay (49.6\%) is highest and followed by Chinese (38.6\%) and Indian (11.8\%). The respondents are mainly from a lower family income which is 127 out of 280. The qualified instructor had taught the respondents mostly to drive by $55.4 \%$. Among the participants, 178 were not stopped by the JPJ.

Table 2. Sociodemographic characteristic of students who met with accident and injuries

\begin{tabular}{|l|l|}
\hline Variable & Yes (\%) \\
\hline Gender & \\
\hline Male & $137(57.8)$ \\
\hline Female & $100(42.2)$ \\
\hline Ethnicity & \\
\hline Malay & $125(52.7)$ \\
\hline Chinese & $84(35.5)$ \\
\hline Indian & $28(11.8)$ \\
\hline Family Income & \\
\hline Low & $108(45.6)$ \\
\hline Middle & $98(41.4)$ \\
\hline High & $31(13)$ \\
\hline Who taught you to drive? & \\
\hline Family Member & $42(17.7)$ \\
\hline Friends & $65(27.4)$ \\
\hline Qualified Instructor & $130(54.9)$ \\
\hline Total & $\mathbf{2 3 7 ( 1 0 0 )}$ \\
\hline
\end{tabular}

Table 3(A). Risk Factors contributing road traffic accidents and injuries

\begin{tabular}{|l|l|l|}
\hline Variable & Met With Accident (\%) & Had Not Met With Accident (\%) \\
\hline Driving Lessons & $171(83)$ & $36(17)$ \\
\hline Yes & $66(90.4)$ & $7(9.6)$ \\
\hline No & $155(79.9)$ & $39(20.1)$ \\
\hline Driving License & $4(5.7)$ \\
\hline Yes & 82(94.3) & $40(19.9)$ \\
\hline No & 161( 80.1) & $3(3.8)$ \\
\hline Wear Seatbelts/Helmets & $76(96.2)$ & \\
\hline Yes & No & \\
\hline If yes, How Often Use Seat belt / helmet \\
\hline
\end{tabular}




\begin{tabular}{|l|l|l|}
\hline Do Not wear & $76(96.2)$ & $3(3.8)$ \\
\hline Seldom & $17(81)$ & $4(19)$ \\
\hline Always & $144(80)$ & $36(20)$ \\
\hline
\end{tabular}

Out of 280, only 237 of them met with accidents and they are mainly males with the leading percentages of $52.7 \%$. Of these, Malays has the highest percentage of $52.7 \%$. The participants who met with accidents and injuries are mostly from low family income of $45.6 \%$. The participants who had knowledge on driving from the qualified instructor met with the most accidents with $54.9 \%$ followed by friends and family member.

Out of 237 respondents, $90.4 \%$ of them did not attend driving lessons, 94.3\% did not have a driving license, and $96.2 \%$ not wearing seatbelts or helmets. From the 161 respondents who wearing seatbelts or helmets, 144 always wear and 17 of them seldom wear seatbelts or helmets

Table 3 (B). Reason for Using and Not Using Seatbelts/Helmets

\begin{tabular}{|l|l|}
\hline Reasons for using seat belts/helmets & (N) \% \\
\hline Prevent from injuries & $113(47.7)$ \\
\hline A habit & $48(20.2)$ \\
\hline Because it is the regulation & $40(16.9)$ \\
\hline Fear of being fined & $31(13.1)$ \\
\hline Reminder from the car sensor system & $5(2.1)$ \\
\hline \multicolumn{2}{|l}{} \\
\hline Reasons for Not using seat belts/helmets & (N) \% \\
\hline Driving short distance & $82(34.6)$ \\
\hline Forgot to put on & $63(26.6)$ \\
\hline Seat belts/helmets are uncomfortable & $33(13.9)$ \\
\hline $\begin{array}{l}\text { Do not want clothes creased / do not want } \\
\text { hair to be messy }\end{array}$ & $23(9.7)$ \\
\hline In a hurry & $21(8.9)$ \\
\hline Driving in a not busy area & $15(6.3)$ \\
\hline
\end{tabular}

Based on the results, the reasons for using seatbelts are to prevent from injuries with a highest percentage of $47.7 \%$ and followed by the others. Surprisingly, $34.6 \%$ of them feel they drive only to short distance and hence they do not wear seatbelts.

Table 4. Association between motor vehicle accidents and injuries towards risk factors

\begin{tabular}{|c|c|c|c|}
\hline \multirow[t]{2}{*}{ Risk Factors } & \multicolumn{2}{|c|}{ Met With Accident } & \multirow[t]{2}{*}{ p Value } \\
\hline & Yes (\%) & No (\%) & \\
\hline \multicolumn{4}{|c|}{ Driving Lessons } \\
\hline Yes & 171(83) & $36(17)$ & \multirow{2}{*}{$\begin{array}{l}* 0.001 \\
\text { (highly significant) }\end{array}$} \\
\hline No & $66(90.4)$ & $7(9.6)$ & \\
\hline \multicolumn{4}{|c|}{ Driving License } \\
\hline Yes & 155(79.9) & $39(20.1)$ & \multirow{2}{*}{$\begin{array}{l}* 0.001 \\
\text { (highly significant) }\end{array}$} \\
\hline No & $82(94.3)$ & $4(5.7)$ & \\
\hline \multicolumn{4}{|c|}{ Wear Seatbelts/Helmets } \\
\hline Yes & 161(80.1) & $40(19.9)$ & \multirow[t]{2}{*}{$\begin{array}{l}* 0.001 \\
\text { (highly significant) }\end{array}$} \\
\hline No & $76(96.2)$ & $3(3.8)$ & \\
\hline
\end{tabular}


E-International Journals of Public Health

Volume 4, Issue 2, 2016

\begin{tabular}{|l|l|l|l|}
\hline Do Not wear & $76(96.2)$ & $3(3.8)$ & \multirow{2}{*}{$* 0.003$} \\
\cline { 1 - 3 } Seldom & $17(81)$ & $4(19)$ & \\
\cline { 1 - 3 } Always & $144(80)$ & $36(20)$ & \\
\hline
\end{tabular}

$* \mathrm{P}<0.05$

Based on the tabulation of data, $90.4 \%$ of respondents had met with accidents is without attending a driving lessons $(\mathrm{P}=0.001)$. Meanwhile, $94.3 \%$ of them did not have a driving license $(\mathrm{P}=0.001)$ and also met with accidents and $96.2 \%$ of them did not wear seatbelts or helmets $(\mathrm{P}=0.001)$.

\section{Discussion}

Based on our study, the road traffic accidents and injuries can be said one of the leading problem in Muar. This is proven from the data analysis when the 280 respondents answered the questionnaires. Our targeted population are form six students from higher secondary schools. The reason we chose this population is because adolescents are the highest age group that causes road traffic accidents. The sociodemograhic results shows that men are the highest gender that cause accidents with a percentage of $90.7 \%$ and the leading race is Malays with a percentage of $89.9 \%$. However, the Proceedings of the Eastern Asia Society for Transportation Studies, Vol. 5, pp. 1867 - 1874, shows the females and the non-malays are the highest percentages that cause accidents with $67.1 \%$ and $74.4 \%$ (Car occupants accidents and injuries among adolescents in a state in Malaysia, 2005)

Out of 280, only 237 of them met with accidents. More than half of the respondents have said that they have met with road traffic accidents and injuries. The participants who met with accidents and injuries are mostly from low family income of $85 \%$. This is because they do not want to spend money on getting a proper knowledge on driving skills and hence do not want to attend driving lessons. When they do not attend driving lessons they do not own a driving license. So there won't be a fair knowledge on driving skills and this causes them to meet with accidents without proper lessons. The participants who had knowledge on driving from the qualified instructor are less likely to meet with accidents. Immaturity, inexperienced particularly in the necessary driving skills and capabilities were the main reasons postulated(Mayhew, 2002) The Swedish national road traffic accidents showed there were more older people who were license holders as compared to the 19 years old(Murray, 2003). Qualified instructor provides learning to drive and preparing the road test in order to produce safer drivers.

Our study shows that not having driving lessons is associated with having injuries as motorcar occupants. The formal driving lessons among these form six students is quite recent (1-2 years) and that could make them more cautious when they are driving and they avoid from getting involved in accidents. At the same time it also can be a factor whereby less experienced drivers do cause accidents. However, a review of 30 studies from several countries reported that formal driving education did not have low frequency of road traffic accidents. Another review from John Hopkins School of Public Health and the Cochrane Injuries group in the United Kingdom also reported no convincing evidence from undergoing driver education (Mayhew, 2002).

There was a significant association between having injuries as motorcar occupants and not having driving license. There is lack of driving skills and experience among those who did not have driving license and driving lessons. Once a person acquires a driving license in Malaysia they are still on probation for two years before they can receive their normal driving license. Most new probation licensed drivers are more careful as they do not want to lose their driving status and opportunity at an early stage. Seatbelts or helmets effectively reduce serious injuries and deaths. In our study, majority of the students used seatbelts or helmets to prevent from injuries and because it's a habit, followed by fear of being fined. The reasons given for not using the seatbelts or helmets were driving short distances, forgetfulness, were in a hurry. (Car occupants accidents and injuries among adolescents in a state in Malaysia, 
2005). This is similar to our study as well whereby the respondents use seatbelts or helmets to prevent from accident with a highest percentage of $47.7 \%$.

There was a relative significant association between motor vehicle accidents and injuries towards risk factors. In our study sample most of the students sustained from serious injuries. Safety seatbelts or helmets usage was higher in primary enforcement cities of Boston, Chicago, Houston and New York (Wells Jk, 2002). Analysis of national probability sample of the United States 1992, usage of seat belt among 12 -13 year, 14-17 year and 18-21 years reported $45.6 \%, 19.8 \%$ and $10.2 \%$ respectively (Brener ND, 1998). The fatality rate for the non-users of seatbelts or helmets was six times greater than that of the belt users for all ages in Kuwait. The non-users required more surgeries and received more abdominal and facial injuries (Koushki PA, 2003). A study in New Zealand reported seatbelts or helmets used as a driver (91\%), front seat passenger (93\%) and rear seat passenger $(40 \%)$. One of the main reasons given for not using seat belts was 'not in the habit' (Begg DJ, 2000).

The current study can be generalized to all form six students in Selangor. However it cannot be generalized for the late adolescents who are out of school or attending private schools who tend to have a different and states of vulnerability towards driving. Being a selfreport, there is the possibility of underestimation of road traffic accidents. A prospective study of these students with driving lessons and driving license who later graduate to the outside world would be very useful in understanding further the trends of road traffic accidents and safety practices among young people (Car occupants accidents and injuries among adolescents in a state in Malaysia, 2005).

\section{Conclusion}

Our study shows that among the 280 respondents, 237 students which are $84.6 \%$ of them had met with an accident. From the 237 students, the most is male students, Malay, and also from a high income family. Our study also shows that there was a significant association between road traffic accident and injuries with not having a driving license, not attending driving lessons and usage of seatbelts or helmets.

\section{Recommendation}

Our government should implement strict rules and tough penalties such as increasing fines and summon to curb traffic accidents. Seatbelts and helmets should be made compulsory by law in our country. Disciplinary actions should also be implemented on drivers such as not wearing seatbelt and helmet while on road.

For the awareness, Schools have a role to play by emphasizing the importance on road safety, like usage of seat belts, proper driving practice by organizing awareness campaigns and seminars which is given by road traffic instructors. The media also needs to draw the attention of all road users both to dangers and to safe practices on the road.

\section{Acknowledgement}

We as authors are thankful to Asia Metropolitan University lecturers, staffs and friends for helping us to conducting this study. We extend our thanks to the respondents and School Staffs for allowing us to conducting the research in the government setting.

\section{References}

[1.] Begg, D. J. and Langley, J. L. (2000). Seat-belt use and related behaviours among young adults Journal of Safety Research, Vo. 131, No. 4, 211-220

[2.] Brener, N.D. and Collins, J. L. (1998). Co-occurrence of health-risk behaviours among adolescents in the United States. Journal of Adolescent. Health, Vol. 22, 209-213.

[3.] Esnizah, M. S. (2008). A study on Road Safety at High Accident Sites and the Development of Accident Prediction Model at Federal Route FT 50 Batu Pahat to Ayer Hitam. UniversitiTun Hussein Onn Malaysia: Bachelor’s Degree Thesis. 


\section{E-International Journals of Public Health}

\section{Volume 4, Issue 2, 2016}

[4.] Fajaruddin, M., Ismail, Y., Ismail, R., Aziz, A. S., \& Esnizah, M. S. (2008). Blackspot Study and Accident Prediction Model Using Multiple Liner Regression. Proc. of the First International Conference on Construction in Developing Countries. Karachi, Pakistan: UniversitiTun Hussein Onn Malaysia.

[5.] Fajaruddin, M. (2005). Treating Hazardous Locations at Federal Route UniversitiTeknologi Malaysia: Master's Thesis.

[6.] Gwynn, D.W. (1967). Relationship between Road Accident and Hourly Volumes, Traffic Quartely. 14(1), pp. 407-418.

[7.] Hejar abdul rahman, Nor afiah Mohdzulkifli, Kulanthayan, subramaniam, Law teik hua, Car occupants accidents and injuries among adolescents in a state in Malaysia, 2005, Vol 5, 1867 - 1874

[8.] Helai, H. \& Mohamed, A. A. (2010). Multilevel data and Bayesian analysis in traffic safety. Accident Analysis and Prevention, 42(2010), page 1556-1565. Retrieved on October 18, 2010, from www.elsevier.com/locate/aap.

[9.] Hizal, H. H. \& Sharifah, A. S. M. R. (2009). The Construction of Road Accident bAnalysis and Database System in Malaysia. Proc. of IRTAD Conference, vol.4. Seoul, Korea: IRTAD.

[10.] Hispanics and Whites. Accident Analysis \& Prevention, Vol 34, 523-529.

[11.] http://www.roadsafetymayo.ie/CausesofAccidents/

[12.] http://www.who.int/mediacentre/factsheets/fs358/en/

[13.] http://eprints.uthm.edu.my/1752/1/mohd_zakwan_ramli2.pdf

[14.]

https://www.researchgate.net/publication/242229814_car_occupants_accidents_and_injuries_among_a dolescents_in_a_state_in_malaysia

[15.] http://www.cph.org.uk/wp-content/uploads/2012/08/road-traffic-accidents-a-review-of-evidencefor-prevention.pdf

[16.] http://www.ncbi.nlm.nih.gov/pmc/articles/PMC2888338/

[17.] http://www.ncbi.nlm.nih.gov/pmc/articles/PMC2586788/

[18.] Institute of Transportation Engineers (2001). Traffic Engineering Handbook. 6th Ed. New Jersey: Prentice Hall Inc.

[19.] Jabatan Pengangkutan Jalan (2010). Statistik Pendaftaran Kenderaan Awam. Retrieved on May 2011 from Jabatan Pengangkutan Jalan

[20.] Koushki, P.A., Bustan, M.A., Kartam, N.(2003) Impact of safety belt use on road accident injury and injury type in Kuwait. Accident Analysis and Prevention, Vol 35, 237-241.

[21.] Mayhew, D.R. and Simpson, H.M.(2002) The safety value of driver education and training Injury Prevention, Vol 8 .Supp II:ii3-ii7.

[22.] Murray, A. (2003). Decreasing number of young license holders and reduced number of accidents. A description of trends in Sweden. Accident Analysis \& Prevention, Vol 900,1-10.

[23.] Ministry of Health Malaysia 1997. Epidemiology of Injury in Malaysia

[24.] Ministry of Health Malaysia. Health Facts 2003.

[25.] Ministry of Health Malaysia. Malaysia’s Health 2002.

[26.] NHSA (1998). Motor-vehicle Occupant Safety Survey 1998

(http://www.nhsa.dot.gov/people/injury/airbags/occupant_safety/AppendixA1.htm)

[27.] Preusser, D.F., Williams, A.F., Lund, A.K. (1987) The effect of New York's seat belt use law on teenage drivers. Accident Analysis Prevention, Vol 19, 73-80.

[28.] Proceedings of the Eastern Asia Society for Transportation Studies, Vol. 5, pp. 1867 - 1874, 2005

[29.] Royal Malaysian Police. Statistical Report Road Accident Malaysia 2002.

[30.] Sanmastri, S. (2006). Audit Keselamatan Jalan Raya Dalam Kampus Universiti Teknologi Malaysia, Skudai. UniversitiTeknologi Malaysia. Bachelor’s Degree Thesis.

[31.] Statistics Sweden, 2001a. Vagtrafikskador 2000 (Road Traffic injuries 2000). Swedish Institute for Transport and communication Analysis (SIKA), Stockholm.

[32.] Wells, J.K., Williams, A.F., Farmer, C.M.(2002) Seat belt use among African Americans, 
South American Journal of Public Health

Volume 4, Issue 2, 2016

[33.] Williams, A.F., Rappold, V., Ferguson, S.A. (1997) Seat belt use by high school drivers and their passengers. J Traffic Med, Vol 25, 21-25.

[34.] World Health Organization 2004. World Report on Road Traffic Injury Prevention, 2004

[35.] Polis Diraja Malayisa (2009). Laporan Tahunan Polis Diraja Malaysia 2008. Retrieved on May 2011, from Polis Diraja Malaysia. 